\title{
Post-harvest Technology and the Reduction of Hunger
}

\section{Michael Lipton*}

Ten years ago, the following five propositions were generally believed:

1. that very large amounts of cereals, typically $30-50$ per cent. were lost between the harvest and the stomach:

2. that such losses were highest in traditional PHT systems. especially on small farms;

3. that modern PHT could drastically reduce these losses:

4. that such loss reduction was economically costeffective for both farmers and society;

5. that a major reduction in hunger could be achieved by reducing grain losses through modern PHT.

In many quarters, this remains the conventional wisdom. Much conventional wisdom is conventional because it is wisdom. But these five propositions seem to be wisdom only because they are conventional. There is now convincing evidence that all five propositions are incorrect.

Unfortunately production planning by PHT suppliers, and economic planning by national and international policy-makers. involve long time lags. In many countries. therefore. major resources (and supporting international efforts) are being diverted into quite inappropriate PHT activities. These activities may well provide work for aid officials and planners. and profits for the makers of modern PHT in the form of silos and mills. The net effect. however, will be to increase grain losses. not least by stimulating crosshaulage: to redirect grain. from efficient on-farm PHT systems, into systems in the private and public surplushandling sectors where incentives to efficiency are much less direct: and, through employment effects among others, to worsen hunger.

Since 1975, IDS has been involved in collaborative research in India and Bangladesh. measuring various sorts of post-harvest paddy and rice losses in 26 villages. In this brief introduction. I would like to put our results into the context of other studies, involving different areas and crops. I will set out the evidence for five propositions about post-harvest grain loss and PHT which are very different from the five beliefs of

*Paper presented at the Post-harvest technology workshop held in New Delhi by the Ministry of Agriculture and Irrigation, Government of India and the Institute of Development Studies in January 1981. ten years' ago, listed above. Finally, I will ask what we can learn from this story of 'conventional wisdom rejected in PHT - a story in which India's scientific and economic expertise, and her extraordinary switch into grain surplus. plays a major part - about the place of technology. and of the planning of technology. in the fight against hunger. In PHT the main lesson is to switch Food Corporation of India (FCI) procurement policy gradually towards the purchase of liens (prior claims) upon grain stored and processed at familyfarm level.

The five propositions, noted above. can now be replaced by the following five:

1. on-farm grain losses. between harvest and consumption. are typically five to eight per cent of grain output, and very rarely above 10-12 per cent. But even these losses cause concentrated suffering just when grain is scarcest. It is worth preventing them if this is not too expensive;

2. losses in traditional PHT systems are typically lower than in modern systems:

3. simple, locally-produced improvements in traditional PHT are often cost-effective, privately and socially, in saving small amounts of grain;

4. heavy, capital-intensive PHT seldom pays; where it does amply cover costs (as with some hullermills), there can be severe social consequences:

5. in particular, even where modern PHT saves grain, and does it cheaply, it tends to displace highly labour-intensive activity, in working traditional PHT and in producing it. The lost employment. especially for landless rural women. may well damage poor people's nutrition much more than the small amounts of saved grain improve it.

\section{Small but Significant Grain Losses}

It is still common to see claims that $30-50$ per cent of harvested grain is wasted. But farmers. especially hungry ones. are not fools. So it is not surprising that. even before our work. the few estimates that actually tried to measure losses produced far lower figures. In the late 1960 s. a five per cent storage loss rate for maize in central Africa. and five to six per cent for maize and guinea-corn in Nigeria. were measured. In 1976-78, in 18 Andhra villages and over 200 stores over two years, we measured average paddy losses in store of 4.26 per cent ( 1.33 per cent at 95 per cent), with an average store life of 7.02 months (ie an average period 
of grain in store, assuming smooth rundown, of 3.51 months). In eight Bangladesh villages over two years, paddy losses in all PH operations totalled below eight per cent. Wheat storage loss rates in the Punjab in the early 1970 s were about six per cent. Other results from India and Nepal and from several SE Asian countries all confirm these sorts of loss-rate for Asian farm households [see refs in Greeley 1982]. As for Africa, the Tropical Products Institute's work on maize in Zambia and Kenya, and Gugenheim's work on millets among the Dogon in Mali, produced similar estimates [Gugenheim 1978]. While exceptionally bad stores and seasons do turn up - and while the last, mouldy remnants of the worst stores are what visitors are shown and remember-all the systematic $\mathrm{PH}$ measurements of storage loss, in the 60-70 per cent of grain typically stored at farm household level in the Third World, are of the order of three to eight per cent. The huge estimates of 30-50 per cent are guesstimates extrapolated from isolated, extreme and thus nonrandom situations.

Similar remarks apply to other $\mathrm{PH}$ operations. For example, most of the grains lost in both threshing and husking are later gathered and eaten by very poor people, and in a social sense are not 'lost' at all.

Why, where and when might it be sensible to try and do something even about these relatively small loses? It is reasonable to suppose, in many cases, that by costeffective technical change, a four per cent storage loss at farm household level can be cut to two per cent. That could, in a typical case, mean one week's grain needs for a family. This week's worth of 'saved' grain is available just when the stock, on the family farm or household, would otherwise run out. In a one-cropseason village, that is often near the end of the wet season, when pre-harvest work is heavy, grain dear, and credit is also dear and scarce. Food needs are highest at this season-also because disease vectors are most prevalent - yet food is hard to come by. Hence, in areas with only one crop season, improved traditional PHT can help very poor people to avoid hunger and debt at critical periods. In multi-crop areas, average periods in store are shorter, so that $\mathbf{P H}$ grain losses are generally lower. But some modern PHT is on its way in, because-especially in milling and threshing -it can pay economically, even with no open or concealed subsidy. Here too, PHT planning, especially of the organisation of ownership and control, is needed if the poor are to benefit. Otherwise they can become the unemployed victims of new PHT.

So there are two main cases where, despite the small losses, major public-sector intervention in PHT is justified. The first is where the losses concentrate risks of hunger, hardship and debt on particular at-risk groups and seasons-especially where double cropping is rare. The second is where modern PHT, while commercially and economically justified, must be planned if employment effects, on those initially working or making older PHT, are not to increase their poverty and hunger. Without intervention, in the first case 'the market' does not enable the poorest to acquire PHT assets, or to suck new techniques out of their fingers. In the second case, 'the market' works all too well, but the poorest suffer.

\section{Loss Rates: Old versus New PHT Systems}

Both old, very small, on-farm PHT, and some largescale modern systems, offer low loss rates due to accurate and swift loss detection and control. Losses in large, properly supervised, permanent grain silos are thus low. So, at considerably smaller costs of loss prevention, are losses in small grain stores in farm households, where insect or rat damage is usually detected and isolated quickly.

Intermediate systems, though, may suffer higher losses than either traditional or modern ones. Loss rates in temporary storage are notoriously high. Engelberg huller-mills cause somewhat higher losses than either mortar-and-pestle or modern rice mills (though, under practical field conditions, the latter are costlier per unit of throughput than huller-mills). Merchant storage and processing in small rural towns, since it involves numerous small and brief grain throughputs, is relatively wasteful, because loss per ton for only a few days is inconspicuous and not easy to detect, even if loss per ton-day is higher than in other, longer-term PHT systems.

In general, to shift grain from traditional (ie usually farm household) PHT systems to modern (usually offfarm) systems is to use up capital-and fuel-in increased cross-haulage - and even (during seasons or years of scarcity) in re-haulage, to the rural areas of origin. Three defences, often advanced for incurring such costs, are the requirements of urbanisation; shifts of farm output to bigger farmers; and concentration of production for surplus in a few 'successful' farming areas.

Urbanisation does require some new PHT outlays. More people who need food now live far from the point of production. Also there are economies of scale avoiding the frequent transport, and addition to urban stores, of numerous small amounts of grain. But this does not make a good case for centralising such operations as milling or hulling. Anyway the true rate of net urbanisation - the growth of the urban share of population - is rather low, not only in India but in most parts of Asia and Africa.

Nor, within rural areas, is there good evidence that cereal output is shifting towards big surplus farms. 
Smaller farms. are. if anything. increasing their share of both land and holdings. That is natural enough. in view of population growth. the threat (if not often the reality) of land ceilings. and the advantages of small farmers in labour-intensive HYV production. The persistence of self-feeding micro-farmers-and villages - removes another alleged 'requirement' for a shift of grain storage. away from user-growers.

However. a major regional shift of cereal output $-\mathrm{a}$ concentration of production-for-surplus in the Punjab. Haryana. Uttar Pradesh and coastal Tamilnadu and Andhra-has taken place. This does entail some centripetal changes in established patterns of grain transport and storage. But changes required in PHT patterns due to other factors. such as urbanisation or (alleged) concentration of land. should not be exaggerated. They do not. in any case. provide a good reason for a major switch to large-scale or capitalintensive forms of PHT. There is a strong case for meeting the needs of at-risk poor and grain-deficit rural areas and producers. to the extent possible. by liens upon the household-level stores of surplus producers: bought (by merchants or $\mathrm{FCl}$ ) at harvest time, but collected later. so that maximum flexibility and decentralisation of stores. and of pre-storage $\mathrm{PH}$ processes. is preserved as long as possible.

In any event. grain will be lost. not saved. if cash is spent on large centralised PHT and on the associated transport. Some such spending is needed. but should be minimised. That is not only because it may waste grain (and fossil fuel) and show poor rates of return. It is also because such policies inevitably shift control and economic power away from small rural grainholders (including small farmers and even some landless labourers) towards grain merchants. managers. and power brokers. both private and public.

\section{Local Improvements in PHT}

Loss rates of only four to five per cent prevail in traditional paddy storage in Andhra (typically about 40 per cent of the loss being due to insects and about 50-55 per cent due to rodents). Yet it pays. both privately and socially. to teach local village builders the sorts of design. siting. and plinth structures that impede rat attacks. It pays too. to fumigate improved traditional stores. Locally-generated improvements seem generally more economic - and. as Tyagi shows | 1981 | much more labour-intensive - than the products of organised industry.

For example. the net social benefit/cost ratios in Andhra villages for metal bins were 1.08 to 1 (or 1.14 to 1 if appropriate up-weighting is given to benefits accruing to poorer groups). However. for improvement to the gade (large bamboo basket) the ratios were respectively 1.44 (1.51 with distributional weights). Social returns on metal bins were much more marginal and. given the costs and alternative uses of credit. probably unattractive. These remarks also apply to the private returns. despite attempts in some places to subsidise metal bins. However, the case for local improvement - and against bins - need not apply in all cases. especially a) if indoor storage is predominant (increasing both bin life. and the vulnerability of lessrobust stores to nearby rats): or b) if big amounts of grain are often held. so that less metal is needed per kg of grain stored. Concrete and ferro-concrete structures are hardly ever economic at farm-household levels.

It is important to distinguish clearly between grain savings. private returns to PHT improvement. and social returns. In Andhra. even smallish grain savings permit quite high private returns. because costs of local improvements are low. Social rates of return are higher still. mainly because improvements can be built in the slack season when labourers have little other work to do. whereas the benefit (saved grain) mostly accrues near the end of the crop year. when food is scarcest. In other circumstances social returns from storage improvement could fall short of private returns. for example if the rats. kept out of my grain store by an improved plinth. merely invaded your store instead: or if. kept out of both our stores. they attacked grain in the field. or in stores in other villages. Where (as in Bangladesh-and perhaps West Bengal) multi-cropping makes average storage periods as short as two to three months. loss rates may be too low to justify in economic terms. even outlays on cheap and locally-made improvements.

There is a widespread sense that important 'hidden gains' exist to improved storage-gains not fully reflected in the low loss-rates reported by almost all scientific studies of farm-level storage. nor in the modest (if sometimes adequate) returns reported on improvements. Such 'hidden gains' indeed exist. but are very unlikely to justify outlay on large modern PHT systems. which seldom save much grain. They do. however. considerably strengthen the case for locally-improved PHT where it might otherwise seem a "close decision". It must always be remembered that policymakers - and farmers - have to choose between spending on PHT and on other investments. eg in field loss prevention or in irrigation: and that these other investments. too. may have "hidden gains". As far as PHT goes. there are three ways in which the gains from loss prevention might be more than is suggested by measured loss-reductions. or by benefit/loss ratios of prevention:

- loss rates in sampled PHT processes or stores might understate true food or value losses in the sample. or omit some indirect sources of loss: 
- reported samples might underestimate countrywide losses;

- the costs of a given loss might exceed apparent levels, due to the distribution of such costs among persons, places or times.

Loss rates in the Andhra and Bangladesh studies are based on weighing all crop movements in and out of store, and crop-store probe samples at regular intervals from loading to exhaustion of the store. Internal insect infestation is deducted from crop weights by the Ashman-Simon method. Tests for the most obvious source of quality loss (uric acid attack, aflatoxins) reveal negligible damage, and expectations of any such damage would any way be reflected in prices (and thus in benefit/cost ratios) if even part of the stored grain were sold. There remain four indirect sources of omitted loss:

1) Weight loss of paddy due to insects-about 40 per cent in Andhra of the 4.26 per cent average loss, viz 1.7 per cent of stored paddy - should be raised by about a quarter at the level of rice loss, to allow for the 'kernel selectivity' of insect pests. Hence about 4.7 per cent of stored rice is lost to all sources of damage.

2) Losses due to infestation continue (probably exponentially) after grain leaves the store. This is significant only if the grain is then not soon eaten, but stored for later consumption. Precision is impossible, but it is very unlikely that such an effect would increase the impact of storage loss at rice level to above five per cent.

3) A five per cent storage loss, for the farmer, is just like a five per cent cut in the price of his threshed product. If it applies to all products, normal priceelasticities of supply would suggest a responsive reduction in output of about one per cent, increasing the true grain loss due to storage effects to about six per cent of paddy.

4) Improved storage would probably increase the offtake of HYVs. Both farmers' complaints and laboratory tests - in Andhra as elsehere - suggest that HYVs, often bred for high grain weight and good germination, are (having thin husks) especially prone to insect pests in storage, and at risk of sprouting in seed store. In this way also, storage losses indirectly cut availability of produced food.

Might our reported loss rates underrepresent farmlevel losses nationwide? We believe not. First, our stratified sampling procedures, we believe, rendered out loss estimates typical of Andhra Pradesh (and in Bangladesh of the two thanas (administrative areas) surveyed, themselves quite typical of their regions). Second, the main single determinant of storage losses may well be the period of storage. This averaged about $31 / 2$ months in the Andhra sample (mean life of store 7 months) and about 2 months in the Bangladesh sample (mean life of store 4 months). Cropping distribution in the Andhra villages, with about 71 per cent of rice produced in kharif and about 29 per cent in rabi, shows about the same concentration as in other areas though in some the proportions would be roughly reversed; hence the $31 / 2$ month average storage period may not be too untypical of paddy in India. (In our Bangladeshi villages, cropping intensity averaged 2.0 as against about 1.5 for all Bangladesh; so the 2month average storage period is probably below average. If the true average is 3 months, then storage loss alone could be about $4 \frac{1}{2}$ per cent for raw and about $3 \frac{1}{2}$ per cent for parboiled paddy, as against the 3.3 per cent and 2.5 per cent figures in our sample). Third, our crop might show untypically low loss rates. But rice is India's main food, and storage as paddy (as in Andhra) involves higher loss rates than storage parboiled. Moreover, the wetter South should feature more intensive pest attack (and more crowding of stores into rat-prone places) than the drier, less-denselypopulated North, and indeed the evidence on wheat - from the Ford Foundation's earlier Punjab study, and from the Delhi Union and Nepali work [reported respectively by Wilson et al 1970, Singh et al 1981 and S. K. Bhalla 1981 ] does not show significantly higher loss rates in store.

However, although we believe that our three to six per cent food loss estimates in farm-level storage accurately reflect the national pictures in India and Bangladesh, we accept that they may underestimate the true cost of these losses, in three ways:

1) The 'grains saved' become available at the season of greatest need, when food would otherwise run out, with credit dear, sometimes compelling debt or mortgage.

2) Loss reduction cuts risk, because storage pests concentrate heavily on selected places and times. For example, in a region of Andhra where one-third of grains are stored in outdoor gades, 6.2 per cent of grain so stored was lost in 1975 but only 3.7 per cent in 1976.

3) Storage improvements normally appear to benefit poor farmers most. (a) Both risk and seasonal impact are most damaging to the poorest farmers who are thus most helped by scale-neutral loss reductions. (b) Unlike output rises, these need not be shared by sharecroppers with their landlords. (c) Poorer farmers store larger proportions of their grain (ie pressures to distress sales are outweighed by the larger proportion of grain needed for own-consumption, and the smaller proportions sold, or used to pay hired labour). In Andhra, farmers operating below three acres stored 62 per cent of paddy output, but farmers with above nine acres stored only 53 per cent - a pattern repeated in Bangladesh. (d) Poor farmers may suffer higher loss rates (perhaps because both fumigation and the shift from traditional to modern structures feature economies 
of scale); in outdoor gades, the main storage type in our Andhra sample, small stores (below 30 bags) lost 5.9 per cent of stored paddy, but big stores (over 60 bags) only 2.5 per cent despite the larger storage period.

So there are several reasons for 'shading upwards' somewhat - though not drastically - both our loss estimates and our benefit/cost ratios. However, storage probably presents the most favourable case for costeffective local PHT improvements. Even here, multicrop villages, with smooth rundowns between each of two or three annual replenishments from harvests, are less attractive for storage improvements, because storage losses are lower. We doubt whether the local improvements feasible in Andhra would show attractive benefit/cost ratios in Bangladesh: partly because Bangladesh's higher cropping intensity reduces average period in store, and thus cuts down insect pest damage before exponential pest population growth has its worst effects; partly because people are even poorer and, in the case of women, more underemployed in Bangladesh and therefore find it pays to make even surer that grain is not lost in store; partly because in Bangladesh, like SW India but unlike Andhra, people often prefer parboiled rice, which has lower loss rates.

In non-storage PHT processes, prospects for costeffective localised improvements seem slenderer. At least half the PH losses, we believe, are in storage. So there is seldom much to be saved by spreading costs over a long sequence of mini-losses-in threshing, winnowing, drying (in most cases), milling, etc. It is true that poor drying can greatly increase losses afterwards, especially via moulds, and that wet harvest conditions impede sun-drying. However, in Bagladesh, large drying losses are so unusual-typically only in one of the three harvest seasons is a really wet $\mathrm{PH}$ a major risk - that it is seldom worth risking the purchase of new drying equipment, which will oscillate between long years of idleness and a few days of overuse and possible breakdown. Moreover, despite much research, no micro-drier, really competitive in wet years with custom drying, for (say) the one to two hectare farmer, has been developed.

In milling, husking etc the problem is different. True loss rates-remember that brokens are not 'lost' but are retrieved and eaten, cheap, by the poorest - are very low with traditional mortar-and-pestle methods. But, per unit of throughput, labour-costs and even capital costs are lower with huller mills (and their 'intermediate' but still costly equivalents for other crops than paddy) than with mortar-and-pestle. There is no technique in sight that can, in the medium term, compete with these semi-modern huller techniqueseven unsubsidised-and be operated efficiently at the level of the one to two hectare farm. For milling, the problem is to find ways of getting ownership or control over the improved capital-or over alternative sources of income-to the traditional PHT operators displaced by it.

As for threshing, pedal-threshers-costing a few hundred rupees - give considerable grain savings (up to $1-1 \frac{1}{2}$ per cent of crop) as compared with animal, road vehicle, etc threshing. A pedal thresher is a farm purchase that, say, four to eight farmers, cultivating one to two hectares each, might consider. Such threshers, that is, not only cut production costs, but - even though they do displace labour-can be owned by the labour they displace. This would not be practicable if land were very unequally distributed, and credit unavailable to deficit farmers and the landless. Otherwise, however, pedal-threshers could comprise an effort-saving (rather than employmentreducing) asset, ownable by very poor rural people, and certainly less harmful to their chances of work and food than threshing-machines. Notice that this discussion says almost nothing about direct impact on food losses. Even more than in storage, the effects of PHT innovations in threshing and milling upon employment and income-distribution are much more important, in determining the outcome for the hungry poor, than the (very small) direct impact on grain availability.

Summarising, in storage-the main, though still small, source of farm-household PH cereal losses-prospects to innovate with locally produced, small-farm-level, employment-intensive, grain-saving technology are good, especially in one-crop areas. In threshing, four to six small (including deficit) farms could together economically operate a pedal-driven improvementdesirable where landlessness and credit-famine are not too serious. Efficient milling technology is somewhat larger in scale; huller mills are often highly efficient, but displace desperately poor traditional, mortar-andpestle custom-millers; really big modern rice mills destroy jobs, do not save grain, and are highly uneconomic in South Asia except when artificially subsidised, as is all too often the case. In milling, as in drying, few really competitive small-scale prospects exist yet-but in drying the rate of return on bigger technology also seems dubious.

\section{The Heavy Options}

Martin Greeley [1980] gives more details of the impact of huller mills on employment, income and poverty in rural Bangladesh. Work by Barbara Harriss [1976] shows that in South India 'modern rice mills' have even more serious effects on poor custom-hullers but are not even efficient, or profitable unless subsidised. As with driers, the uneven flow of throughput across 
places, seasons and years is the main reason. So much capital is locked up, with no alternative uses, a fixed working life, and little physical mobility.

The FCI, following up a major government commissioned programming exercise, have developed a siting plan for long-term grain stocks. Given a 20-25 per cent urban population, export possibilities in some years, grain stocks again heading for $20 \mathrm{mn}$ tonnes, yet deficit years like 1979-80, only a fool will dismiss the need for some heavy-capital-intensive urban stores, specially since there are major economies of scale in building materials, fumigation, and stock control as stored quantity rises. Yet I wonder if enough thought has been given to the option of leaving the grain, bought up by FCI or by private merchants, in farmhousehold stores until required. The gains-in flexibility, personal overview, decentralisation, and saved cross-haulage-could well outweigh the lost economies-of-scale. That is especially the case when both energy costs and transport bottlenecks appear to worsen at unpredictable rates and times. 'Optimal' location of big grain stores can look, suddenly, very wrong if big uncertainties exist. For example, if there is a sudden rise in the output of only some crops in some places, the ability to use - or to create-widely dispersed on-farm capacity is worth more than a lot of existing but unfortunately located silos.

In the immediate post-harvest stage, heavy options are two: the combine harvester and the reaper-binder. The days of World Bank subsidies to combines are, happily, over. Threshing machines attached to tractor motors, are, however, often seen in the Punjab, andprobably pay well, even without hidden subsidies to fuel, credit or machinery. Yet plainly they displace employment. There are two ways round this. A capitalist solution would be to encourage more migration in the threshing seasons, keeping wage-rates down so that it did not pay to displace labour with machinery; this solution is less inhumane than it seems, because the wage bill (employment times the wage-rate) is certainly higher this way than with the labour-replacing 'Punjabi solution', once the shortage (and temporarily high wage-rate) of migrant labour has induced labourreplacing mechanisation. A socialist solution would involve joint ownership and management of the threshing machines by the displaced workers. What economists have to see is that these problems demand social solutions, whether capitalist or socialist. If the 'heavy' technology uses more capital and less labour, price adjustments (even just desubsidisation) can make it unattractive. But if the 'heavy' technology uses less labour and less capital, it is likely to be a winner. Its benefits are real and need spreading. Its employment effects cannot be solved by fiddling with prices alone. But, as explained. the intermediate option - the pedal thresher-does provide an option. Its cost is low enough for joint ownership by 'the poor' to be feasible.

No such obvious intermediate option is available in milling. For rice, traditional technologies do seem to be 'inferior' to huller mills, which use less labour and less capital. The problem, acutely, is whether the political and social system can provide assets-not necessarily, though perhaps most plausibly, in PHT - complementary to the labour of the persons displaced. Experience with women's cooperative ownership in the Cameroons and Bangladesh, provide some grounds for hope.

\section{The Effect on Hunger}

In one-crop systems, and with especially valuable food crops, small-scale and locally-made storage improvements can be a cost-effective way to save significant (though not sensational) amounts of grain - and to do so in such a way that poor people avoid costly loans, and purchases, in hungry times. But many, perhaps most, PHT innovations - especially 'heavy' ones, which take work from landless and near landless people-tend to increase hunger. There is little saved grain, sometimes none, and many jobs are lost.

Most PHT improvements that come onstream are designed to save labour. They are developed for rural areas in rich countries, where, even in slump, labour is often scarce and dear. The greatest caution and selectivity must be exercised in applying such innovations to developing rural areas, which normally feature low wages, high unemployment (especially among the poorest and in slack seasons), and scarce capital. The need for caution, in respect of PHT with high capital/labour rates, should also affect the productmix. For example, the introduction of soya beans in order to improve nutrition can be doubtful policy, because the relatively expensive processing equipment soaks up savings that could otherwise pay for capital to produce food directly-and does so through machinery that employs fewer people than does directly food-producing equipment (eg minor irrigation devices).

\section{Do Lower Farm-level Losses Suggest Decentralised PHT?}

India now has very large public-sector grain stocks. A good rabi in 1981 would bring them to $20 \mathrm{mn}$ tons or even more. Past experience shows that sudden surges in central stocking requirements bring heavy losses in temporary stores, serious transport bottlenecks, and otherwise steeply-rising marginal costs. Moreover, good and bad harvests do not alternate in convenient fashion. A succession of good harvests, as in 1975-78, means increasing strains and losses for centralised $\mathrm{PH}$ storage and handling systems, both public and private. 
A succession of poor harvests can then sharply deplete or exhaust stocks, already subject to severe deterioration in the case of supposedly 'temporary' crop-storage that had been prolonged during the period of good harvests, ever-increasing inflows, and unexpectedly small offtakes. When Joseph predicted 'seven fat years followed by seven lean years' and advised precautionary storage, his biblical secretaries did not, alas, record how he dealt with this problem. Centralised access to large stores will remain necessary.

I should like to propose that India's procurement and public purchase agencies handle this problem by gradually shifting their grain procurement and stocking policy away from total stress on huge centralised stores, towards the purchases of liens upon grain stored by farm households. This proposal starts from two observations. First, it does not follow from the fact that central stocks (in whatever condition) are now big, that substantial run-downs are welcome. Particular regions can experience near-disaster before others have gathered their seasonal crop, even if that latter crop is excellent and the national average outturn for the year outstanding. 'Bad' national averages can follow each other, while population continues to rise. Meanwhile, we all hope that in India both real income-per-person and the share of its total income going to poor people will rise; but as they rise, so does demand for grains. So the apparently large grain stock is at risk of prolonged, and perhaps suddenly savage, local and even national depletion. If the proposed Indo-Soviet 'oil for wheat' barter deal goes through, one hopes that a break clause in the event of simultaneous bad harvests in India and the USSR (as in 1972) will be incorporated; otherwise India might again face severely depleted stocks, sky-high world grain prices and a bad harvest all at once, but this time aggravated by export commitments. But we start with the observation of a large, vulnerable and necessary centralised access to grain - together with big, rising costs in centralised physical location, build up and run-down of such grain.

The second observation-arising from the work in Andhra, Bangladesh and elsewhere reported in this article - is that loss rates in small on-farm grain stores are already low, but that there are often high social and private returns to research, technology and extension designed to cut these on-farm losses down still further through locally-produced, labour-intensive improvements. Analogous observations apply to other PH processes, though farm-level losses (true losses, not broken or shedded grain retrieved by others) in some such processes may be so small that there is more doubt about the economic viability of improvements.
From these two observations - the need for centralised access to grain, greater cheapness, loss-reduction, economic efficiency, energy-saving, and benefits to poor people, from decentralised, farm-household $\mathrm{PH}$ storage and processing of grain-a strong policy conclusion follows. Public, centralising authorities responsible for handling grain (notably FCI) and analogous private concerns (notably large urban grain merchants), should modify their present policies of physically procuring large amounts of grain at harvest, storing (and often processing) that grain centrally, and then re-selling it - usually to urban markets near the central store, but not infrequently to the very rural areas that sold them the grain in the first place. Instead, public authorities should decide-and private firms should be stimulated by price policies - to purchase, from the farm household at harvest time, claims upon some of the grain itself, or the option to buy it if needed during a given period, while leaving to the farmer-against payment - the costs of threshing, drying, storing, and in many cases milling or hulling the grain.

It is not a valid objection to say either 'the farmer needs the money' or 'the farmer will not supply the grain to the purchaser when it is claimed'. These worries cancel each other out. If, for example, FCI buys a lien on the grain, the farmer would receive the full purchase price indeed, if FCI expects to buy (say) three to six months after the harvest, it could pay rather more than the harvest price, for the right to collect the grain at any time up to, say, eight months after harvest, whatever the market price. If FCI chose the policy of buying only an option to purchase the grain at harvest price during those eight months, it could lend the farmer the difference between the price of the option and the harvest price of grain-perhaps at a slightly concessional rate. In both cases, FCI would raise the purchase price to allow for storage, and perhaps other processing costs, borne by the farmer. Corresponding to such transactions, the farmer would be obligated to deliver grain, in good condition, as stated. There is no reason to believe that the costs, leakages, etc-which there undoubtedly would be-would exceed those from current policies of centralisation of stocks, cross-haulage and rehaulage.

Of course, any shift to such a lien system should be gradual, and at first experimental. But it should be stressed that the experiment should apply for five to six years, being extended earlier if clearly successful, but not being abandoned because of teething troubles. It is important to see how the lien system compares with centralised location over a series of years of fluctuating stocking/destocking requirements. Also the lien experiments should not be confined to surplus regions or surplus farmers; poorer areas and poorer 
farmers, now compelled (by the need to pay debts) to make big sales (with physical crop movements) immediately after harvest and to buy later, might gain most, and provide most cost-effective PH overview, in the lien system. Finally, the system's prospects of success would be greatest if it were linked to fieldlevel research and extension involving the economic costs and benefits, private and public, of locallyproduced improvements to 'traditional' $\mathrm{PH}$ systems. Both the Indian Grain Storage Institute and the Save Grain Campaign could benefit from FCI support, while FCI could further cut its costs and its grain losses.

These proposals, or similar ones, are not new. They have been the subject of prolonged, though not published, debate between, and perhaps within, the Planning Commission and the Department of Food. Since that debate took place, however, several things have happened to strengthen the case for replacing, at least experimentally, a significant and growing part of centralised FCI grain stocks by stocks owned by FCI (or covered by options so owned), but located at farm level. First, the energy-costs of present patterns of grain haulage, with its intense seasonal peaks (the Khanna market in the Punjab is an extreme case), have become increasingly unacceptable. Second, the associated grain losses - in transport and in temporary storage - have proved unexpectedly large. Third and perhaps most important, the alleged vast post-harvest losses, associated with the alternative of farm-household storage of procured grain, have been shown, beyond reasonable doubt, to be largely mythical. For these reasons, there is a strong case for considering again, and more favourably, as shift towards on-farm storage (and gradual movement, as needed) of FCI grain requirements; and for incentives to encourage merchants' purchases to be similarly adjusted. This case, it should be stressed, is completely independent of the views one may hold about the role of public or private sectors in the grain trade, or about the need for centrally-owned grain stocks.

\section{References}

Adams, J. M. and G. W. Harman, 1977, 'The evaluation of losses in maize stored on a selection of small farms in Zambia with particular reference to the development of methodology', Report of the Tropical Products Institute, G 109

Bhalla, S. K., 1981, 'Programme on prevention of farm-level storage losses in Nepal and its economics', paper presented at the CIRDAP/IDS conference on rural technology, rural institutions and the rural poorest, Comilla, Bangladesh, February 1981

Greeley, M., 1980, 'Rural technology, rural institutions and the rural poorest : the case of rice processing in Bangladesh', paper prepared for the CIRDAP/IDS conference on rural technology, rural institutions and the rural poorest, Comilla, Bangladesh, February 1981 and published in the Bangladesh Development Studies special issue on food policy and development strategy in Bangladesh, vol 8 nos 1 and 2

-1982 , 'Farm-level post-harvest food losses: some different evidence', CERES, no 85 , vol 15 no I

Gugenheim, Hans, 1978, 'Of millet, mice and men: traditional and invisible technology solutions to post-harvest losses in Mali' in David Pimental (ed), World Food, Pest Losses, and the Environment, AAAS Selected Symposium 13, Westview Press, Boulder, Colorado

Harriss, B., 1976, 'Paddy processing in India and Sri Lanka: a review of the case for technological innovation', Tropical Science, vol 18 no 3

Singh, R. P., G. S. Ram and A. S. Sirohi, 1981, 'An economic analysis of storage of wheat on farms in union territory of Delhi', Division of Agricultural Economics, Indian Agricultural Research Institute, New Delhi*

Tyagi, D. S., 1981, 'Choice of technique for prevention of farm-storage losses: some issues', Agricultural Prices Commission, New Delhi.* Both papers presented at a workshop, sponsored by the World Hunger Programme and the German Agency for Technical Cooperation (GTZ), New Delhi, January 1981

Wilson, H. R. A., et al, 1970, 'Rural wheat storage in Ludhiana', Ford Foundation Staff Document, New Delhi 